\title{
CONJUROS TEUTONES PARA GANAR EN EL AMOR Y EL JUEGO
}

\author{
Xochiquetzalli CRUZ \\ Universidad Nacional Autónoma de México \\ adissarosa@gmail.com
}

\section{RESUMEN}

Este artículo postula que el uso simbólico de los animales, a través de la magia, sirvió como argumento por parte de la élite hegemónica hispana para señalar a los extranjeros como objeto fóbico, es decir, una suerte de receptáculo metafórico donde depositar los miedos hacia los otros, para justificar y explicar así ciertas situaciones adversas de una colectividad. Como muestra, pensemos que para los novohispanos era necesario buscar "un chivo expiatorio" al cual culpar del poder del demonio que avanzaba de manera inconmensurable sobre sus territorios; y qué mejor sujeto para centrar sus temores que los extranjeros: alemanes, italianos, galos, entre otros ${ }^{1}$.

\section{PALABRAS CLAVE}

Extranjeros, hechicería, fetiches, Inquisición, México.

\section{TEUTON CONJURSTO WIN IN LOVE AND THE GAME}

\begin{abstract}
Foreigners are constituted that symbolic use of the animals, through the magic, that is to say, a kind of metaphorical receptacle where to deposit the fears towards the others, to justify and to explain certain adverse situations of a collectivity. As a sample, let us think that for the novohispanos it was necessary to look for "a scapegoat" to blame for the power of the demon that advanced immeasurably over its territories; and what better subject to focus their fears than foreigners: Germans, Italians, Gauls, among others.
\end{abstract}

\section{KEYWORDS}

Foreigners, sorcery, fetishes, inquisition, Mexico.

Recibido: $9 / 4 / 2017$

Aprobado: $15 / 10 / 2017$

1 Este artículo es parte de una investigación doctoral que busca identificar la función de los animales como vehículos culturales y literarios en 6 casos inquisitoriales de México a través del siglo XVIII. 


\section{El documento}

a denuncia y tres testimonios de los soldados españoles Miguel Muñoz, Gerónimo García y Juan de León -pertenecientes al Séptimo Regimiento del Batallón de Granada- contra su compañero, el soldado alemán Agustín Kelin, por supersticioso, se encuentran resguardados en el Archivo General de la Nación de México bajo la signatura, 2579; Vol. 1131 exp. 4 fols. 116r-117v (1776). Entre los cargos imputados al teutón, se encontraron los siguientes: primero, hacer un sortilegio para ganar al juego usando un corazón de murciélago o con una avecilla muerta; segundo, un hechizo para hacerse bien querer de las mujeres utilizando una rana y un hormiguero; por último, un sortilegio de invisibilidad donde se utilizan los huesos de un gato negro.

Descritos los delitos, detectamos en los documentos que a lo largo de las declaraciones los testigos describen dos aspectos. Por un lado, las cualidades físicas de Kelin: se dice que es pelirrojo y rollizo. Por otro, las cualidades morales: se cuenta que huyó a los 8 años de casa de sus padres, que eran herejes, probablemente luteranos, para convertirse en cristiano; además, se acota que es usurero, "gran borracho" y jugador. Finalmente, se presume que cumple con los ritos católicos (confesarse e ir a misa), aunque no lo hace de manera voluntaria, sino que se lo ordenan como a todos los demás soldados, y por eso los efectúa.

Por lo anterior, y a partir de la descripción del documento, es fundamental para el desarrollo de la presente investigación, delinear el contexto cultural, religioso y social que rodea a esta denuncia con el fin de proporcionar una interpretación simbólica plausible sobre el animal empleado en cada uno de los tres hechizos, basándonos en los conceptos de imaginario propuestos por Jacques Le Goff y en los indicios planteados por Ginzburg.

\section{Ser extranjero en la Nueva España en la segunda mitad del siglo XVIII}

Durante la segunda mitad del siglo XVIII, la Nueva España se encontraba en una época muy agitada. Valdría la pena recordar que los gérmenes de la Independencia se estaban gestando entre la población novohispana; y que, además, la implantación de la Reformas Borbónicas, impuestas por Carlos III, tenían descontentos a sus súbditos americanos. En este marco, el recelo tanto de los peninsulares establecidos en México como de los novohispanos hacia los extranjeros era acendrado. Las antiguas estructuras españolas, como la Inquisición, se aferraban a su pasado en un intento desesperado por conservar unido a un cuerpo social que se fragmentaba. Esto, aunado a la propagación del espíritu de renovación impulsado por el pensamiento ilustrado, proveniente del país galo, provocó que las élites de la cultura hegemónica novohispana -es decir, la minoría española y cristiana- intentaran ceñirse a sus viejas instituciones:

Los procesos seguidos contra herejes, bígamos, solicitantes y blasfemos se multiplican durante este periodo, lo que prueba que las "desviaciones" heterodoxas aumentaban sensiblemente por el influjo de los vientos de la nueva mentalidad ilustrada que se caracterizaba por el rechazo a los patrones ancestrales de conducta, 
por su cuestionamiento a las antiguas creencias y por su actitud crítica ante todo tipo de autoridad (Baudot y Méndez, 9).

Dado este celo inquisitorial contra las nuevas ideologías, uno de los objetos fóbicos de los dominicos fueron los extranjeros. Así lo demuestran los casos contra corsarios ingleses, mencionados por Alberro (225). En ese mismo sentido, Consuelo Maqueda ha señalado que el funcionamiento del tribunal se concentró en la investigación sobre los extranjeros que se internaban en la Nueva España, para contener una posible oleada de nuevos estándares ideológicos; con ello, se evitó una posible contaminación de las conciencias de los novohispanos (12).

Los extranjeros se constituyen como un objeto fóbico, es decir, una suerte de receptáculo metafórico donde depositar los miedos hacia los otros, para justificar y explicar así ciertas situaciones adversas de una colectividad. Como muestra, pensemos que para los novohispanos era necesario buscar "un chivo expiatorio" al cual culpar del poder del demonio que avanzaba de manera inconmensurable sobre sus territorios; y qué mejor sujeto para centrar sus temores que los extranjeros: alemanes, italianos, galos, entre otros.

En especial, se ejerció mano dura contra los teutones, debido a que fue en Alemania donde Lutero y su herejía florecieron. Se puede rastrear la semilla de esta aversión en el siglo XVII, ya que, por ejemplo, el Arzobispo Juan de Palafox y Mendoza -quien viajó a territorios germanos durante la guerra de los 30 años (1618-1648)-, en su Dialogo político del Estado de Alemania (1665), calificó los estados germanos "como el asilo de la herejía y seminario de la maldición", un lugar bárbaro e inseguro "lleno de delitos y crueldades [...] setina [o excusado] de Lucifer"(Mayer, 210). Como consecuencia, ser foráneo fue el pretexto idóneo para ser objeto de la condena y la estigmatización, o al menos, así lo demuestra otro caso similar al que estudiamos de 1772 de otro soldado valenciano perteneciente al regimiento de Saboya, llamado Onofre Polito Bonada ${ }^{2}$ al que una presa llamada Ana María Jáuregui le imputaba el mismo delito de invisibilidad que a Agustín Kelin.

Al acaecer la pérdida de la Habana y de Manila en 1762, el régimen peninsular designa a Juan de Villalba y Angulo para salvaguardar los intereses y territorios de la Corona. Estos hombres desembarcan en Veracruz en 1764 (Cruz, 77), lo que acarrea también la llegada de regimientos profesionales a la Nueva España. Entre ellos llegó el Segundo Batallón de Granada en el cual viajaba Agustín Kelin. Ahora bien, los ciudadanos alemanes establecidos en la Nueva España fueron blanco del escrutinio público, porque provenían de esa tierra de pecado y perdición. Y dada la existencia de dos casos contra extranjeros, esto nos sugiere, desde mi punto de vista, que resulta común en los expedientes la utilización simbólica del animal (gato, rana, hormiga, ave) como un agente temible que se inserta dentro del sistema de creencias de los habitantes del Virreinato de manera negativa, con el propósito de construir mediante los animales una visión de mundo donde lo mágico es temido y tildado de reprobable.

En este punto, y de acuerdo con los datos propuestos, podríamos plantear las siguientes preguntas: ¿cuáles eran las creencias de los inquisidores? y ¿por qué consideraron tan censurables estos actos? Para responder a estas cuestiones, partamos del concepto de

2 Este caso es transcrito y rescatado por Mariana Masera en Relatos populares de la Inquisición, p. 275. Véase bibliografía. 
imaginario que acuñó Jaques Le Goff como "el conjunto de representaciones y referencias -en gran medida inconscientes- a través de las cuales una colectividad (una sociedad, una cultura) se percibe, se piensa e incluso obtiene de ese modo una imagen de sí misma que da cuenta de su coherencia y hace posible su funcionamiento" (I).

En conformidad con esta idea, los dominicos, que fueron parte de la cultura hegemónica ${ }^{3}$ junto con la nobleza, afianzaron su estabilidad política y social con base en el dogma cristiano; y dada su función de guardianes de la fe, rechazaron cualquier conducta que pareciera "sospechosa" o rebelde; así, es un hecho indudable que la religión permeaba significativamente las prácticas cotidianas y oficiales de la vida novohispana, por lo que su influencia se dejó sentir en todos los ámbitos de la vida. Por tanto, el Santo Oficio, al percatarse del cambio intelectual del siglo XVIII, respaldó al dogma y a la institución. De esta manera, actuó con "mano dura" contra aquellos disidentes que pertenecían a las culturas secundarias o limítrofes, como las castas (mulatos, indígenas, zambos, coyotes, etc.); o contra aquellos individuos que se alejaran del "buen camino" indicado por las Sagradas Escrituras. Esta forma de proceder de la Inquisición afectó tanto a los extranjeros y criollos como a los peninsulares.

En este escenario de represión e intolerancia, las prácticas alternativas se tacharon de "perversas" y los heterodoxos sufrieron las consecuencias. Se les impuso, de manera individual y colectiva, un "[repudio] religioso, un miedo político social, y un desprecio por la persona misma; siendo, el acto, el grupo y la persona, los blancos de rechazo, y en contra de los cuales ejercían el odio, la exclusión y la represión" (Ortega, 265). A este respecto, los documentos requisados por la Inquisición que estudiaremos y que se constituyen como documentos privilegiados del imaginario son resultado de este amedrentamiento (Le Goff, III); pese a que se trata de escritos jurídicos, podemos estudiarlos como manifestaciones literarias dada la naturaleza vaporosa (flove) del imaginario que "no está solo vinculado con otros dominios, sino que literalmente se interpreta con ellos" (Le Goff, III).

Así, entre sus líneas se entretejen representaciones o "la traducción mental de una realidad percibida. [Ésta] implica un proceso de abstracción, que es igualmente un proceso creativo. De esta manera, la representación de algo se transforma en la idea que tenemos acerca de algo" (Le Goff, IV). Dichas abstracciones constituyeron parámetros literariosimbólicos que encarnaron en la mente de los inquisidores, como el infierno en la Tierra, cuando creyeron ver, por ejemplo, en los individuos "disfuncionales" a los acólitos del Diablo y sus poderes mágicos. En efecto, la magia, la hechicería y la brujería fueron las prácticas imputadas por los poderes oficiales, ya que tenían ciertos intereses personales, religiosos o políticos, para quitar del camino a estos elementos socialmente incorrectos, como fue el caso de Agustín Kelin, un individuo considerado indeseable.

\section{Hechizo con un gato negro}

De los cuatro delitos imputados al teutón, se encuentra el mencionado por Muñoz, el primer testigo:

3 Alvarado Ojeda define esta idea de la siguiente forma: "la hegemonía es un término que designa la superioridad de un elemento (individuo, grupo político, religioso, social, económico) sobre otros y puede ser material, cultural o social ly cuenta con dos elementos fundamentales] la coerción y la capacidad de convencer, de penetrar con las ideas y valores del sujeto dominante a los dominados" (1). En línea: https://prezi.com/sk5blrndjhqi/cultura-hegemonica-y-subalterna/. 
que como dos semanas estando de guardia una noche en el Palacio del Virrey, hablando los dos solos, el declarante y Agustín Kelin, sobre el modo de tener dinero, dijo Agustín: eso no tiene dificultad. Se coge un gato negro chico y se pone en una olla bien tapada al fuego hasta que se consuma y queden solo los huesos. Y llevándolos una noche al campo, llamar al Demonio y si se quisiera meter en cualquier casa donde halla dinero, el que llevare los huesos se haría invisible (Folio 123r).

El posible origen del sortilegio sugerido por Kelin a Muñoz puede ser rastreado en la difusión importante que tuvieron los grimorios (libros de magia y hechicería) en Europa durante el siglo XVIII; gracias a esta particularidad, este hechizo puede detectarse en obras como las Clavículas de Salomón y el Cipriano o el Ciprianillo que tuvieron gran distribución en Europa central. Así, el probable camino de trasmisión del ensalmo siguió varias rutas, quizá llevado por los soldados trashumantes, ya que se descubrieron importantes centros protestantes en Sevilla y Valladolid (1558). Se supone que estos soldados llegaron, primero, a Granada; posteriormente, parten de Sevilla para la Casa de contratación; y, más tarde, se embarcan hacia el Nuevo Mundo, vía Veracruz, con lo cual los grimorios alcanzaron una gran difusión en la Nueva España:

Contrario a lo que se pueda creer, según los expedientes de la Inquisición y los autos de fe, las personas que poseían y leían los grimorios eran personajes de la élite novohispana; funcionarios de la corona, oficiales del ejército, clérigos, comerciantes y libreros. La demanda de este tipo de literatura provocó la formación de un "mercado negro" de libros, donde los métodos para introducir los grimorios prohibidos variaban, según las circunstancias de la época (Howey, 1).

\section{¿Por qué un gato negro?}

En conformidad con lo anterior, se pueden encontrar vestigios de la utilización del gato negro en la magia de culturas muy antiguas:

La mitología celta habría sido la forma favorita de los demonios que ponían en peligro a los héroes en sus maravillosas aventuras. Junto con los peligrosísimos cerdos y las hormigas tan grandes [...] los mordaces gatos se encontraban entre los oponentes de los valientes celtas. La Iglesia cristiana creyendo aumentar su poder incorporó estos conceptos monstruosos a su propia demonología de modo que la superstición medieval reconoció un diablo disfrazado en cada gato negro (Howey, 212).

Por otra parte, el color del animal se asemeja al de las tinieblas. De esto nos habla San Isidoro: "las brujas se llaman así debido a lo negro de su culpa, es decir, que sus actos son más malignos que los de cualquier otro malhechor" (Etimologías, cap. 9). Desde este pensamiento analógico, al ser estos animales del mismo color adquirían lo maligno de los actos, que se reflejan en sus merodeos y forma de apareamiento, además de que su maullido se parece al grito de un niño pequeño. Esto contribuyó a que se le temiera, pues "estas creencias prevalecían aún en las zonas más recónditas de Europa. Podemos 
[citar], como ejemplo a los campesinos del sur de Eslovenia quienes están firmemente persuadidos de que el Diablo habita un gato negro" (Howey, 219).

Este imaginario permea significativamente en el ideario brujeril, el cual plantea que los gatos serán los acompañantes, transportes y familiares de las brujas en los aquelarres. Por estas razones, citaré a continuación tres versiones del hechizo para constatar, por un lado, la variación y enriquecimiento del conjuro a lo largo del tiempo y, por otro, para comprobar que la significación de este animal persiste en el siglo XVIII novohispano. En primer lugar, encontramos el hechizo en el Ciprianillo ${ }^{4}$, que a la letra dice:

"Magia de un hueso de la cabeza de un gato negro"

Pon a hervir un caldero de agua con leña de vides blancas y de sauce, y cuando vaya a romper el hervor mete dentro de ella un gato negro, vivo, dejándole cocer hasta que se aparten los huesos de la carne. Realizada esta operación, sácanse todos los huesos con un paño de hilo y colócase la persona que está haciendo esta suerte delante de un espejo, metiéndose hueso por hueso en la boca hasta que la imagen de la persona que realiza esta operación desaparezca del espejo, lo que supondrá que ese es el hueso que tiene la virtud de hacer invisible a la persona que lo llevare en la boca. Cuando quisiera asir a alguna parte sin ser visto os meteréis el hueso en la boca y diréis: Quiero estar en tal parte por el poder de la magia negra. Es de advertir que no hay necesidad de introducirse en la boca todo el hueso para hacer la prueba del espejo, basta apretarlo poco con los dientes (149).

Además de la utilización del gato se agregan otros elementos como las uvas y el sauce ${ }^{5}$, plantas a las que se atribuían cualidades mágicas. A continuación, tenemos un antecedente, un caso semejante, el caso del soldado Onofre Polito en 1772 que Mariana Masera transcribió:

4 Con respecto a la concepción y escritura del Ciprianillo, Peter Missler apunta, en su artículo intitulado "Las hondas raíces del Ciprianillo. 2a parte: los grimorios", lo siguiente: "Puede que no sea éste el espacio idóneo para que nos adentremos en la difícil y complicada cuestión de la génesis del Gran Libro de San Cipriano, de su datación y de su bautismo con el nombre del Santo de Antioquía. El Gran Libro de San Cipriano es, en realidad, la peor pesadilla que puede sufrir un filólogo. Tiene tantos antepasados como descendientes, tantas influencias como ramificaciones, y los detalles acerca de su nacimiento han quedado ocultados por el tiempo. Me limitaré a decir que creo, con Barreiro de Vázquez Varela y con otros investigadores, que no quedó afianzado ningún texto con el nombre de "San Cipriano" antes de la segunda mitad del siglo XVIII. Aparte del hecho, en sí mismo significativo, de que no se documente el título hasta el año 1802[6], llama la atención -por mucho que se trate de un arriesgado "argument from silence"- el hecho de que ninguno de los grandes comentaristas acerca de la magia de los siglos XVI al XVIII -Del Río, Ciruelo, Castañega, Feijoo- mencione el título, aunque todos tuvieron a su alcance una abundante información acerca de los grimorios, y conocían, además, y a fondo, la leyenda de San Cipriano"(I). Por lo tanto, dada la datación y su difusión fue muy probable que estuviera al alcance de la gente de a pie como Kelin.

5 Este árbol era considerado pieza fundamental del bagaje mágico celta o al menos así lo afirma Conway en su libro Magia celta, pues le atribuye propiedades de protección y suerte, ya que la "(Salix alba) [Es]uno de los siete árboles sagrados de los irlandeses y árbol sagrado también para los druidas. El sauce es un árbol de la Luna consagrado a la Dama Blanca. Sus bosques eran considerados mágicos, tan es así que los sacerdotes, sacerdotisas y todo tipo de artesanos iban a sentarse entre sus árboles para conseguir el don de la elocuencia, inspiración, habilidades y dotes para profetizar. Si queréis que se os conceda un deseo, pedid permiso al sauce y explicádselo. Elegid un brote que se pueda doblar y haced con él un nudo flojo mientras expresáis lo que queréis. Cuando el deseo os haya sido concedido, volved y soltad el nudo. No os olvidéis de dar las gracias al sauce ni de dejarle un regalo" (199). Así siendo un árbol sagrado no fue extraño que aparezca en este contexto simbólico. 
De allía poco tiempo volvió y le dio [Ana Jáuregui] tres reales para que le comprara una olla, unas velas, carbón, iesca eslabón y piedra. Lo que ejecutando, lo pasó todo a una casa vieja y bacía, donde Polito la esperaba. Llegada que fue a dicha casa, y entregado todo al referido, éste se quitó el rosario y comenzó aprender lumbre y donde afirma la nominada que arrojó los santos evangelios y no sabe que otras cosas sagradas, pues él sólo le dijo necesitaba aquella obra de barias reliquias lo que le abia conseguido de un sacristán que no sabe de dónde es. Después de esto, puso la olla al fuego, en la que echó el gato vivo. Cosido que fue, lo comenzó a pelar y dessollar, y todo esto decía era para hallar la cabeza del gato un gueso llamado invisible, pues con él se conseguía el que, traíendolo en la boca, se bolbía uno invicible y entraba y salía a todas partes. Y barios guesillos se metió en la boca. I luego se miraba a un espejo, diciendo que entonces lo habían de llamar por su nombre, más que el no había de voltear la cara, porque entonces no sabe la nominada lo que decía abía de ver el referido (Masera, 275).

Unos años más tarde vamos a encontrar este mismo conjuro en el Diccionario Infernal (1818) de Jacques Colin de Placy:

Salomón nos descubre importantes secretos para la incivilidad. Hácese invisible llevando sobre su brazo derecho el corazón de un murciélago, el de una gallina negra y el de una rana; ó bien robar un gato negro, comprar una vasija nueva, un espejo un eslabón, una piedra de ágata carbón y yesca, observando ir á sacar agua á media noche es una fuente, hecho lo cual se enciende el fuego, se mete el gato en la vasija se tiene tapada con la mano izquierda sin moverse jamás ni mirar atrás por cualquier ruido que se oiga y después de haberle hecho hervir por espacio de 25 horas, pones en un plato nuevo se toma a vianda y se arroja por encima de la espalda izquierda diciendo esta palabras: Accipe quod tibi do nihil amplius; luego después se ponen los huesos uno después de otro bajo los dientes del costado izquierdo, mirándoos en el espejo: y si el hueso que teneis no es el bueno arrojadlos sucesivamente hasta que se haya encontrado; al momento en que no se vea en el espejo se retirará reculones diciendo: Pater in manus tuas conendo spiritum meum (136).

Por lo anterior, es indudable que el empleo de la osamenta de este animal para lograr la invisibilidad proviene de tradiciones antiguas; asimismo, las cualidades que se le atribuían son gracias a su conexión con el mundo infernal y el Demonio. En consecuencia, este hechizo se considera como un documento interesante para la historia literaria novohispana, pues nos muestra las creencias que todavía amoldan, construyen y perviven actualmente.

\section{Hechizo para ganar el amor de una fembra con una rana}

En segundo lugar, Kelin aconseja a Joachim de la Peña que, para hacerse bien querer de cualquier mujer, ponga una rana muerta en una cajita con polvos, que la horade y la coloque a las dos de la tarde cerca de un hormiguero. Después, le dijo, se retirará inmediatamente, porque si la rana croaba, se quedaría sordo. También le advirtió no voltear la vista, escuchara lo que escuchara. Posteriormente, le dijo que regresara por 
la caja cumplidas 24 horas; así encontraría dos huesitos: uno con el cual podría hacerse querer de cualquier mujer con solo rozar su ropa y el segundo servía para lo contrario. Así descrito el conjuro, resulta indudable que toma en cuenta las características intrínsecas del animal y del ars amatoria.

Aquí, cabría preguntarnos ¿por qué desde tiempos remotos los animales han sido utilizados con fines mágicos? Para contestar debemos observar que, a lo largo de la historia, la presencia de los animales resulta innegable en el ideario de la humanidad. En consecuencia, al superar la primera etapa de contacto, es decir, cuando dejaron de ser vistos como mero alimento o peligro potencial, los animales se transformaron en un receptáculo ontológico que permitió explicar al ser humano no sólo su propio entorno físico, sino también el espiritual y emocional, con el objetivo de complementar su visión de mundo. Ejemplos de lo anterior son la representación de un hombre con cabeza de pájaro en la cueva de Lascaux (Francia) o la zoomorfización de Apuleyo en El asno de oro.

Por tanto, esta carga simbólica-social de los animales va acrecentándose al transcurrir el tiempo. Como muestra tenemos los estudios biológicos sobre la naturaleza, realizados por los filósofos griegos en la antigüedad. Andando el tiempo, las bestias se convierten en referentes de la conducta humana: funcionan como el vínculo analógico de lo terrenal y lo divino, de ahí la encarnación de Cristo en el Agnus Dei, por ejemplo. De esta manera, cuando la representación de los animales opera en niveles significativos dentro de los sistemas simbólicos -como el psicológico, el histórico, el religioso y el literario-, la magia funciona como un procedimiento para re-consolidar la relación entre mundo y humanidad. Por esa razón, para Manilowski la magia constituye "un corpus de actos puramente prácticos que son celebrados con un fin" (76).

La afirmación anterior se comprueba cuando se observa que en el pensamiento primitivo el brujo o bruja, al manipular los elementos naturales mediante ciertas prácticas, buscaban obtener un fin específico, como en el caso de nuestro hechizo. En otras palabras, al ser la magia un sistema simbólico "[éste] es un trasunto de la propia ontología del hombre" (Cencillo, 236) y, por tanto, sirve como puente, mediante la naturaleza, para tener una significación profunda en su visión de mundo. Es decir, Kelin cree firmemente en que Peña podrá obtener el amor de cualquier mujer. De allí que del inventario de elementos que utilizaba el hombre en este ritual, se encuentren animales, minerales y plantas, los cuales servían como conexión con el fin de unir lo natural y lo humano, para así elevarlo a la esfera de lo espiritual. Por ese motivo, resulta plausible que en los manuales de zoología aparezcan bestias con atributos extraordinarios, ya que su presencia, a menudo, fue necesaria en los rituales religiosos, los altares y las pócimas mágicas.

Al emular los acontecimientos naturales mediante un ritual, lo magii sustituía a la bestia con alguna de sus partes; entonces, este simulacro re-construía el medio y los fines podrían lograrse. En este contexto, los animales se convirtieron -gracias a sus comportamientos y a su carga simbólico-tradicional- en referentes sociales, imaginarios y literarios. De esta manera, es muy plausible que tanto la rana como las hormigas se erigieran como puentes para lograr un anhelo. Me parece que el posible origen de este conjuro sería el mismo que el anterior, es decir, los grimorios que tuvieron gran difusión en la Nueva España y en especial El Ciprianillo, ya que uno de sus capítulos se intitula "Filtros, hechicerías y 
sortilegios", el cual trata sobre encantamientos producidos por la virtudes y cualidades de los sapos. Tiene una nota que dice: "tanto en este hechizo como el anterior, el sexo del sapo deberá ser del mismo a que pertenece la persona contra quien se hace el hechizo" (140). En la misma obra el santo menciona que este anfibio "tiene una gran fuerza mágica invencible en el momento en que es la comida que Lucifer da a las almas que están en el Infierno" (Charro, 3).

\section{¿Por qué la rana?}

Comencemos, pues, por rastrear la presencia de este anfibio en las diversas fuentes tanto históricas como literarias. Desde el pensamiento antiguo hasta el medieval, y con base en la teoría de los humores, "el agua es fría y húmeda, la tierra seca y fría, el fuego caliente y frío y, finalmente, el aire es húmedo y caliente", nos dice Empédocles. Entonces, este batracio constituye una cruza entre dos de los cuatro elementos: agua y tierra. Por tanto, el mismo Claudio Eliano afirma que estos anfibios se generaban del lodo. En resumen: la naturaleza del batracio presenta varias características: frialdad, sequedad y humedad; y de estas cualidades, destacó la frialdad cuando se compara a este animal con la mujer porque según Galeno "la mujer es más fría que el hombre, lo que es causa de su imperfección" (Canet, 2). Otra característica mujeril de este animal nos la proporciona Cirlot al afirmar que es "[un] animal lunar" (385). Dada la naturaleza fría y huidiza de las ranas no fue extraño que Quevedo las equiparara con las dueñas, así lo atestigua un fragmento de su obra Sueño del infierno:

Yo, que tenía gana de ver todo lo que hubiese, pareciendo que me había detenido mucho, me partí. Y a poco que anduve, topé con una laguna muy grande como el mar, y más sucia, adonde era tanto el ruido, que se me desvanecía la cabeza. Pregunté lo que era aquello, y dijéronme que allí penaban las mujeres que en el mundo se volvieron en dueñas. Así supe cómo las dueñas de acá son ranas del infierno, que eternamente como ranas están hablando, sin ton y sin son, húmedas y en cieno, y son propiamente ranas infernales. Porque las dueñas ni son carne ni pescado, como ellas. Dióme grande risa el verlas convertidas en sabandijas tan perniabiertas y que no se comen sino de medio abajo, como la dueña, cuya cara siempre es trabajosa y arrugada" (RodríguezCacho, 79)

Con adjetivos como pierniabierta y "y que no se comen sino de medio abajo", Quevedo destaca en este fragmento otra característica atribuida a la naturaleza perversa de las mujeres: la lujuria, porque gracias a su piel pegajosa las ranas están siempre lúbricas. Por estas razones, fue muy congruente que el hechizo de Kelin retomara una rana porque siguiendo a la segunda característica de la magia que plantea Frazer: "aquellas cosas que han estado en contacto siguen ejerciendo influencia mutua una vez separadas". Luego, una rana sería el mejor ingrediente para enamorar a una fémina porque tienen naturaleza parecida.

Para reforzar lo anterior, la Iglesia cristiana relacionó la apariencia y usos de este animal con la lujuria y al fornicio porque "en el mundo románico, de arraigado y profundo 
simbolismo, se representa con frecuencia a la mujer lujuriosa con sapos que le succionan un seno, como muestran las portadas de las iglesias de Santa Cruz de Burdeos y la de Charlieu (Loira). Su modo de acoplamiento observado en la naturaleza ha dado origen al pecado capital de la lujuria" (Charro, 4). Además, si partimos de la idea que Dios:

[e]n su magnanimidad, creó todo lo que existe y todo lo bello fue creado por él. La fealdad no podía ser obra de su mano que resumía la perfección. De ahí que lo supuestamente repugnante, lo abyecto, se atribuyera siempre al diablo. Seres horripilantes y deformes fueron contrapuestos a los de origen divino, y si el murciélago resulta la paloma de Satán, el sapo continuó siendo la gallina del diablo. Dentro de la tradición cristiana, el sapo -criatura presuntamente maligna- no podía ser otra cosa que obra del diablo (Charro, 3).

Para terminar, debemos destacar que en este contexto amatorio es común utilizar, en la magia, a los animales como sustitutos del amante. Este cariz está presente en el Ciprianillo, pues abundan los hechizos donde se pretende despojar a la persona deseada de toda voluntad, al realizar ciertas ligaduras sobre el batracio, tales como coserle los ojos y la boca (para impedir que tenga voz propia y vista para otra persona) ${ }^{6} 0$ ataduras en las ancas con el fin de evitar que se aparte de su lado. De ahí las siguientes palabras: "Por el poder de Lucifer [...] te cocí los ojos que es lo que debía hacer para que no tenga sosiego ni descanso en parte alguna del mundo sin mi compañía y ande ciego para todas la mujeres u hombres. Véame únicamente a mí y en mí solo tenga su pensamiento" (140). De este modo, la rana, al ser un animal lúbrico y "pierniabierto", representa el vehículo idóneo para obtener mediante su osamenta el favor sexual de una mujer.

Por su parte, el hormiguero representa quizá una "boca que lleva al inframundo", debido a su naturaleza telúrica, subterránea. Las coordenadas espaciales de los pueblos primigenios detallan este espacio como el lugar donde van las almas al acaecer la muerte. En el caso del dogma cristiano, se equiparó este reino con el infierno donde gobierna el Diabolos. Se trata de un sitio donde corren ríos de azufre (Apocalipsis, 20:15); donde los ángeles recogerán de su reino a todos los escandalosos y a los que comenten la iniquidad para arrojarlos al horno de fuego; en suma, en ese sitio reinará allí el llanto y el rechinar de los dientes (Mateo, 13:41-42). Las hormigas son habitantes, pues, de este inframundo; por ello, al devorar a la rana demuestran su hambre desmesurada y destructiva, además de su conexión con el demonio.

Ahora bien, la creencia de que el croar de la rana producía sordera tal vez se remonte al grito de la mandrágora que al ser arrancada emitía un alarido, pues si alguien escuchaba ese grito, fenecía. En este caso, el hechizo resulta más leve: sólo se quedará sordo al escuchar ese croar del infierno, porque la pobre rana:

Si en el árbol genealógico de la evolución de las especies constituye el grupo filético más primitivo de los vertebrados superiores, en el de la superstición y la leyenda su antigüedad corre pareja y es que el hombre, frente a la característica fealdad del batracio, sintió temor hacia la bestia. En su mentalidad primitiva halló en la adoración

6 Esta práctica aún persiste en la imaginería popular de la actualidad por lo menos en México. 
y el respeto una manera de conjurar sus poderes sobrenaturales, de forma que en el transcurso de los siglos devino en persecución tenaz, a la que se sobrepuso este anfibio, dispuesto a congraciarse con quienes injustamente lo habían vilipendiado y escarnecido (Charro Gorgojo, 13).

\section{Fetiches para ganar en el juego}

Otros consejos que da nuestro soldado a sus compañeros de batallón consisten en tres hechizos para ganar en el juego, dos de los cuales utilizan animales. Para empezar, el procedimiento para hacer funcionar dichos fetiches fue colocarlos "[de]bajo [d]el altar y se les dejará ahí para "escuchara[n] tres veces misa". Así, uno de los testigos, Gerónimo García, efectuó dicho conjuro con una moneda, pero no funcionó. Ante ello, este compañero le reclamó a Kelin, por lo que el teutón le indicó que lo reintentara, pero ahora invocando tres veces al Demonio. A pesar de estas adiciones, García no logra ganar en los albures. En esta parte, el texto menciona la primera variante de estas artes mágicas: Agustín recomienda al jugador que siga el mismo procedimiento para activar el artefacto, pero ahora con una avecita muerta que le entregó arropada en un papel; de hecho, Kelin le aseguró que esto lo auxiliaría, sin duda, a ganar; aunque dicha argucia parece funcionar durante un tiempo, al final fracasa.

Posteriormente, Kelin aconseja una segunda variante, la cual consiste en sacarle el corazón a un murciélago; luego, el interesado debía traerlo como reliquia colgada al cuello. Una vez descritos los conjuros, resulta interesante observar cuán singulares son los ingredientes que utiliza el teutón en sus consejos. De tal manera, es primordial rastrear, primero, la utilización de los fetiches y su uso para comprender como opera la ars mágica en estos casos. Consideramos que un primer indicio subyace en la inversión del ritual cristiano porque, como apunta Alejandro Campagne, la metáfora del espejo - o de un mundo al revés- sostuvo el imaginario demonológico y maniqueo cristianos; en otras palabras: se fijaba la idea de "una iglesia invertida a la que podían atacar sin contemplaciones" (45). En relación con la idea de que existía un Dios perfecto, bondadoso y magnánimo, se antepuso entonces lo contrario: un ser negativo, imperfecto y maligno, es decir, el Demonio. En consecuencia, resultó lógico que sus rituales resultaran antagónicos:

Las brujas se reunían en los sabbats, rito presidido por el Diablo, se arrodillaban frente a él arrepintiéndose de sus pecados, como asistir a misa, y acto seguido eran castigadas por medio de azotes, después se llevaba a cabo la misa negra donde se profanaba la Cruz pisoteándola, la comunión se hacia con un líquido nauseabundo mezclado con la cenizas de infantes calcinados y sangre; la hostia era un objeto parecido a una suela de zapato, la misa terminaba cuando las brujas besaban el ano del Diablo. La danza y el banquete comenzaban, culminando con una orgía en donde el Diablo copulaba con cada uno de los asistentes, los cuales se retiraban a sus casas volando sobre escobas, palos o azadones comprometiéndose a asistir a los siguientes Sabbats (Russell, 54).

De acuerdo con esta cita, es muy lógico pensar que la moneda, la avecilla y el corazón "escucharán misa" porque funcionan como un fetiche:"un objeto natural o inanimado al que 
se le atribuyen fuerzas demoniacas. Lo esencial del fetiche radica no en su naturaleza, sino en su significado oculto al ser portador de un ser demoníaco animiforme" (Vázquez Hoys, 175). Así, en este objeto, podemos observar directamente la intervención del Diabolos. Tal vez de ahí surge la prosopopeya lingüística en primera persona "tenía que escuchar misa". También habría que apuntar la aparición del número tres como el número de veces que tenía que escuchar misa; desde mi punto de vista, esto resulta una clara alusión a la Santísima Trinidad, pues con este acto se llevó a cabo la inversión.

\section{¿Por qué el corazón de un murciélago?}

En principio, el uso del corazón de esta criatura en ciertos rituales de hechicería estriba, precisamente, en que es el órgano donde reside la vida y todos los impulsos vitales (Cirlot, 150). Por tanto, constituye la parte adecuada en la que se deposita todo el simbolismo asociado a este quiróptero. Un semantema a destacar vinculado con el murciélago es el medio donde se desenvuelve: la obscuridad, la noche, así como la hora del día donde las tinieblas ocultan y arropan las prácticas prohibidas. De ese modo, en el Malleus maleficarum, se expone que "[y] así en ese ocaso y anochecer del mundo, en que florece el pecado por todos lados y en todas partes, en que la caridad se enfría, sobre abundan las obras de los brujos y sus iniquidades" (21).

Se cree que, en este mismo lugar, las brujas acechan y matan a los infantes; "asimismo el miedo e incertidumbre de las familias que en las noches vivieron la visita de la mujer maligna" (Netzahualcoyotzi, 116). Centrando nuestra atención en el murciélago en sí, Charro Gorgojo nos señala que el miedo, asco y repulsión hacia este animal se debe a la "general aversión que acompaña a estos animales [que] ha de atribuirse a sus hábitos nocturnos, a su semejanza con los ratones, a su atemorizadora estructura facial, a la extraña conformación de sus extremidades o al ámbito siniestro de sus refugios. Su extravagante aspecto ha hecho que la imaginación popular los convierta en animales de mal agüero, compañeros inseparables de brujas y duendes" (1). En este mismo sentido, Gubernatis nos dice que "el carácter maléfico y demoníaco de las Estriges [llamadas brujas, posteriormente] es compartido por los murciélagos y los vampiros" (35).

Así pues, no fue extraño que las partes que conformaran el cuerpo de este animal -asociado a la obscuridad y a la muerte- se usaran como ingredientes mágicos; por ejemplo, en el Picatrix, obra que versa sobre astrología y que fue traducido por Alfonso X, "el Sabio", en el siglo XIII, "se ofrece una lista de sustancias mágicas con propiedades. maravillosas, entre las que figuran el cerebro de abubilla y la sangre de murciélago" (Charro, 6). Esta tradición es seguida por Celestina en la Tragicomedia de Lisandro y Roselia, donde se contabiliza este efluvio entre todos los afeites y abinículos que la vieja alcahueta tenía en su "laboratorio" (Charro, 7). Por todo lo anterior, el jugador creyó firmemente en que podría mudar su suerte a su beneficio, ya que la rueda de la fortuna es ambivalente; por ello, y con la ayuda del Demonio, consideró que podía hacerse de un poco de dinero, siguiendo los consejos de Kelin. 


\section{BIBLIOGRAFÍA-HEMEROGRAFÍA}

Alberro, S. (1988). Inquisición y sociedad en México 1571-1700, México: Fondo de Cultura Económica.

Baudot, G. y M. A. Méndez (1998). Amores prohibidos. La palabra condenada en el México de los Virreyes, México: COLMEX.

Campagne, A. (2000). "El otro entre nosotros. Funcionalidad de la noción de supertitio en el mundo hegemónico cristiano (España siglo XVI-XVII), en Bulletin Hispanic, Tomo 102, 2000, pp. 37-63" en línea: http://www.academia.edu/9625767/_El_otro-entrenosotros._Funcionalidad_de_la_noci\%C3\%B3n_de_superstitio_en_el_modelo_ hegem\%C3\%B3nico_cristiano_Espa\%C3\%B1a_siglos_XVI_y_XVII_

Canet, J. L. (1996). "La mujer venenosa en la época medieval” en Parnaseo, en línea: http://parnaseo.uv.es/Lemir/Revista/Revista1/Mujer_venenosa.html

Cencillo, L. (1973). Expresividad y lenguaje, Madrid: Complutense.

Cirlot, J. E. (1997). Diccionario de símbolos, Madrid: Siruela.

Colin de Placy, J. (2009). Diccionario Infernal, Versión Facsimilar, Valladolid: Maxton, en línea: https://books.google.com.mx/books?id=plc3LimVOggC\&printsec=frontcover\&d$\mathrm{q}=$ diccionario+infernal\&hl=es419\&sa=X\&ved=0ahUKEwj67ua50qvNAhUEIIIKHYf6CrlQ6AEIHTAA\# $\mathrm{v}=$ onepage\&q=diccionario\%20infernal\& $\mathrm{f}=$ false

Conway, D.J. (2002). Magia celta, Barcelona: Ediciones Obelisco.

Charro Gorgojo, M. A. (2000). "Sapos: historia de una maldición" en Revista de Folklore, № 235, pp. 1-10 en línea: http://www.funjdiaz.net/folklore/07ficha.php?id=1875"Murcielago: príncipe de las tinieblas" en Revista de Folklore, №. 220, 1999, pp. 1-11.

Cruz Barney, O. (2006). "Las milicias en la Nueva España: la obra del segundo Conde de Revillagigedo (1789-1794)" en EHN, México: UNAM, 34, enero-junio, México: UNAM, 73-116.

Gubernatis, A. de (2002). Mitología zoológica. Los animales del aire, Barcelona: Olañeta.

Howey, M. O. (1991). El gato en la magia, la mitología y la religión, tr. Violeta García, Barcelona: Edicomunicación.

Sufurino J. El libro de San Cipriano. Tesoro del hechicero, México: Ciencias ocultas, s/a.

Le Goff, J. (1988). L'imaginaire medieval, Essais, París: 1985, pp.149-261, en Georges Duby, Mâle, Moyen Age. De l'amour et autres essais, París.

Malinowski, B. (1993). Magia, Ciencia y Religión, Planeta-Agostini.

Maqueda Abreu, C. (1998). "Los conflictos de competencias. Una muestra en el tribunal inquisitorial de Nueva España" en La Supervivencia del derecho español en Hispanoamérica durante la época independiente, México: UNAM, IIJ.

Masera Cerutti, M. (2010). Relatos populares de la Inquisición, Madrid: Consejo Superior de Investigaciones Cintíficas/UNAM.

Mayer, A. (2008). Lutero en el Paraíso. La Nueva España en el espejo reformador, México:UNAM/ $\mathrm{FCE} / \mathrm{IIH}$.

Missler, P. (2006). "Las hondas raíces del Ciprianillo. 2a parte: los grimorios" en Culturas Populares, Revista Electrónica 3, septiembre-diciembre, en línea: http://www. culturaspopulares.org/textos3/articulos/missler.htm 
Nezahualcoyotzi Méndez, M. (2015). “'Mordida de bruja o enfermedad? Las muertes de niños en un pueblo tlaxcalteca (México) 1917-1922" en Revista de Historia Regional y Local, Vol. 7, No 13, enero-junio, pp. 112-145."

Ojeda Alvarado, A. "Hegemonía y subalterno" en línea: https://prezi.com/sk5blrndjhqi/ cultura-hegemonica-y-subalterna/

Rodríguez-Cacho, L. (2002). "Ciertas enemigas de Quevedo: las batracias y lashembrilatinas" en La Perinola, Vol. 16, pp. 75-95 en línea: perinola/article/view/4624/3984

Russel, J. (1998). Historia de la brujería. México: Paidós.

San Cipriano (1985). Libro Magno de San Cipriano, Tesoro del Hechicero, Barcelona: Ediciones Humanitas.

San Isidoro de Sevilla (2004). Las Etimologías, Madrid: Biblioteca de Autores Cristianos.

Sprenger J. y E. Institoris (2004). Malleus maleficarum: Martillo para las brujas, trad, y notas de Miguel Jiménez Moteserín, Valladolid: Maxton.

Vázquez Hoyos, A. M. y Ó. Muñoz M. (1997). Diccionario de magia en el mundo antiguo, Madrid: Aldebarán. 